\title{
PERCEPÇÃO DA FIGURA PATERNA FRENTE AO ALEITAMENTO MATERNO*
}

\author{
Déa Silvia Moura da Cruz', Isa Nery Silva Batista dos Santos Rocha², Daniela Karina Antão Marques', \\ Ilana Vanina Bezerra de Souza ${ }^{3}$
}

\begin{abstract}
RESUMO: Considerando a importância do Aleitamento Materno surgiu a necessidade de investigar a participação e a percepção dos pais diante da prática do Aleitamento Materno. Pesquisa do tipo exploratório-descritiva com abordagem qualitativa, realizada na Maternidade Frei Damião, no município de João Pessoa-PB com 10 pais em abril de 2011. Observou-se que a maioria dos pais se mostraram bastante interessados e empenhados em efetuar essa nova tarefa de auxiliar as esposas, pois conheciam as vantagens do aleitamento materno, porém, alguns deles não tinham tal conhecimento, e também não se incluíam nesta prática, referindo ser um momento apenas da mãe e do bebê. Existe a necessidade de inserir a figura paterna nas atividades de educação em saúde desenvolvidas durante o pré-natal e o puerpério, e as que se seguem na puericultura, uma vez que os cuidados com o bebê são de responsabilidade do casal.
\end{abstract}

PALAVRAS-CHAVE: Aleitamento materno; Pais; Percepção.

\section{THE ROLE OF FATHERS IN BREASTFEEDING}

ABSTRACT: Considering the importance of breastfeeding, the necessity arose of investigating the fathers' participation in, and perception of, breastfeeding. This exploratory-descriptive research with a qualitative approach was carried out in the Frei Damião Maternity Hospital in the county of João Pessoa-PB with ten fathers in April 2011. It was observed that the majority of the fathers were quite interested in and committed to carrying out this new task of helping their wives, as they knew the advantages of breastfeeding. Some of them however did not have this knowledge and equally did not include themselves in breastfeeding, saying it was a moment for the mother and baby alone. There is a necessity for fathers to be included in health education activities taking place in the pre- and post-birth periods and those which follow in childrearing, as caring for a baby is the responsibility of the couple.

KEYWORDS: Breast-feeding; Fathers; Perception.

\section{PERCEPCIÓN DE LA FIGURA PATERNA DELANTE DEL AMAMANTAMIENTO MATERNO}

RESUMEN: Considerando la importancia del amamantamiento materno surgió la necesidad de investigar la participación y la percepción de los padres delante de la práctica del amamantamiento materno. Investigación del tipo exploratorio-descriptiva con abordaje cualitativa, realizada en la Maternidad Frei Damião, en municipio de João Pessoa,PB, con 10 padres en abril de 2011. Se ha observado que la mayoría de los padres se mostraron muy interesados y empeñados en efectuar esa nueva tarea de auxiliar las esposas, pues conocían las ventajas del amamantamiento materno. Sin embargo algunos de ellos no tenían ese conocimiento y tampoco se incluían en esta práctica, afirmando ser un momento sólo de la madre y del bebé. Existe la necesidad de inserir la figura paterna en las actividades de educación en salud desarrolladas durante el prenatal y el puerperio, y las que se siguen en la puericultura, una vez que los cuidados con el bebé son de responsabilidad de la pareja. PALABRAS-CLAVE: Amamantamiento materno; Padres; Percepción.

\footnotetext{
*Artigo original extraído de Trabalho de Conclusão de Curso apresentado em 2011 na Faculdade de Enfermagem Nova Esperança -FACENE, João Pessoa-PB.

${ }^{1}$ Enfermeira do Hospital Universitário Lauro Wanderley. Mestre em Enfermagem. Professora do Curso de Graduação em Enfermagem da FACENE.

${ }^{2}$ Enfermeira.

${ }^{3}$ Enfermeira da Maternidade Frei Damião. Mestre em Educação. Professora da FACENE.
} 


\section{INTRODUÇÃO}

O aleitamento materno (AM) é muito importante para o desenvolvimento humano, pois fornece proteínas, açúcares, gorduras e vitaminas, suprindo todas as necessidades do lactente até o sexto mês de vida, e do sexto ao décimo segundo mês é um importante suplemento na dieta infantil ${ }^{(1)}$.

É muito importante que haja incentivo às mães para que elas possam obter sucesso na amamentação. No início do terceiro trimestre de gestação o profissional de saúde responsável pelo pré-natal da gestante deve informar todos os benefícios e como obter sucesso durante a amamentação ${ }^{(2)}$.

A presença da figura paterna é muito importante durante toda a gestação e amamentação, porém, a sociedade o visualiza apenas como suporte financeiro, dificultando a criação e vínculo pai-filho. Assim, é importante que o pai participe de cada momento da amamentação, pois seu apoio deixa a mãe bastante encorajada, vindo assim a favorecer o sucesso do $\mathrm{AM}^{(3)}$.

A paternidade está ligada diretamente à lactação, pois o pai pode interferir neste processo, positivamente ou negativamente, tudo depende do grau de informação e do seu envolvimento. Vale ressaltar o valor afetivo, pois para o homem há o envolvimento de vários sentimentos, como: bem-estar, frustração e exclusão, no contexto familiar em que o mesmo está inserido ${ }^{(4)}$.

Considerando-se a importância do pai no sucesso do AM, esta pesquisa teve como objetivos conhecer a participação do pai na prática do AM e investigar sua percepção diante da prática.

O estudo poderá contribuir para a reflexão sobre a importância do pai na prática do AM; nos entraves que interferem na sua participação e na sua responsabilidade na promoção da saúde do binômio mãe-filho.

\section{METODOLOGIA}

A pesquisa foi do tipo exploratório-descritiva com abordagem qualitativa, realizada na Maternidade Frei Damião, localizada no Município de João Pessoa-PB. A amostra foi constituída por 10 pais escolhidos aleatoriamente, que aceitaram e formalizaram a participação na pesquisa.

A coleta de dados foi por meio de entrevista, com roteiro pré-estabelecido, no mês de abril de 2011, após aprovação do projeto pelo Comitê de Ética e Pesquisa da Faculdade de Enfermagem Nova Esperança. Os resultados foram analisados através da Técnica do Discurso do Sujeito Coletivo (DSC) ${ }^{(5)}$ e discutivos de acordo com a literatura pertinente ao tema.

A pesquisa respeitou os aspectos éticos em Pesquisa Envolvendo Seres Humanos, contidos na Resolução 196/96 do CNS - Ministério da Saúde e a Resolução 311/2007 do Conselho Federal de Enfermagem (COFEN), sendo submetido e aprovado Comitê de Ética em Pesquisa da FACENE, sob Prot.232/2010.

\section{RESULTADOS}

Em resposta ao questionamento: o que você sabe sobre aleitamento materno? Os pais apresentaram os DSC que se apresentam no quadro 1.

Quando questionados sobre como poderiam participar na amamentação do seu filho, observou-se os DSC contidos no quadro 2 (p. 704).

Baseado nas respostas ao questionamento, se a amamentação interferia positivamente ou negativamente no seu relacionamento com sua esposa e por quê, foi construído o DSC apresentado no quadro 3 (p. 704).

Quadro 1 - Conhecimento do pai quanto ao aleitamento materno. João Pessoa, 2011

\section{IDEIA CENTRAL 1 Discurso do Sujeito Coletivo 1 \\ É o alimento mais [...] as crianças que não se ama- saudável e ajuda nas mentam direito vão sofrer um defesas do organismo. bocado através de doença [...]. Tem anticorpospraminhafilhaeémais saudável. [...] ele está adquirindo imunidade, seu organismo está criando defesas para os diversos tipos de doenças.}

IDEIA CENTRAL 2 Discurso do Sujeito Coletivo 2 É uma alimentação [...] alimentação que a criança que a criança deve deve ter rigorosamente de um ter rigorosamente a seis meses [...]. Até 6 meses a até o sexto mês de criança não precisa de outra vida. alimentação.[...]tudo que o bebe precisa até o sexto mês de vida.

IDEIA CENTRAL 3 Discurso do Sujeito Coletivo 3 É o alimento essen- [...] amamentação é essencial, trás cial para a criança, saúde pra criança diferente desse melhor que os outros outro leite, que não tem a subsleites, mais saudável tância que o leite materno tem. É e mais completo. saudável e tem muita vitamina. [...] é o melhor de todos.[...] alimento mais completo que existe.

IDEIA CENTRAL 4 Discurso do Sujeito Coletivo 4

Desconhece. [...] não sei nada. 


\section{DISCUSSÃO}

De acordo com os DSCs apresentados no quadro 1, observou-se que grande parte dos pais percebiam a amamentação como um algo muito importante para o bebê, e conheciam suas vantagens. Reconheciam que o leite materno proporciona à criança uma vida mais saudável, tendo em vista que é rico em proteínas, vitaminas, carboidratos, gorduras e outros nutrientes. Porém, observou-se que um dos pais não tinha qualquer conhecimento sobre a importância do AM, podendo esta falta de informação comprometer o sucesso deste, uma vez que os pais podem ser grandes motivadores de suas companheiras.

O AM pode diminuir consideravelmente os níveis de mortalidade infantil, considerando que o aleitamento deve ser exclusivo e, se possível prolongado, proporcionando à criança uma melhor qualidade de vida ${ }^{(6)}$.

O leite materno é extremamente importante para o RN, pois o mesmo atende suas necessidades nutricionais, psicológicas e imunológicas ${ }^{(7)}$.

Além da proteção contra doenças infecciosas o AM tem um papel muito importante no que se refere

Quadro 2 - Percepção do pai quanto sua participação no aleitamento materno. João Pessoa, 2011

\begin{tabular}{|c|c|}
\hline $\begin{array}{l}\text { IDEIACENTRAL1 } \\
\text { Incentivando a es- } \\
\text { posa a amamenta- } \\
\text { ção, dando apoio e } \\
\text { carinho. } \\
\text { IDEIA CENTRAL 2 } \\
\text { Oferecendo a esposa } \\
\text { uma alimentaçãomais } \\
\text { saudável, para que ela } \\
\text { produza um bom leite. } \\
\text { IDEIACENTRAL3 } \\
\text { Ajudando a esposa } \\
\text { em todos os momen- } \\
\text { tos de necessidade. }\end{array}$ & $\begin{array}{l}\text { Discurso do Sujeito Coletivo } 1 \\
\text { [...] incentivar a mulher a amamen- } \\
\text { tar. [...] incentivar a todas as mães } \\
\text { a amamentar. [...] dando apoio e } \\
\text { carinho. [...] incentivar bastante a } \\
\text { minha esposa. } \\
\text { Discurso do Sujeito Coletivo } 2 \\
\text { [...] uma alimentação mais sau- } \\
\text { dável para minha mulher. [...] } \\
\text { alimentando ela para ela gerar } \\
\text { um leite sadio. } \\
\text { Discurso do Sujeito Coletivo } 3 \\
\text { [...] ajudar a esposa quando esta } \\
\text { com bastante leite nos seios. [...] } \\
\text { sempre vou ajudar minha esposa. } \\
{[\ldots . .] \text { auxilio minha esposa no que }} \\
\text { for necessário. [...] ajudando a } \\
\text { minha esposano que ela precisar. } \\
\text { Discurso do Sujeito Coletivo } 4 \\
\text { [...] é um momento só para a } \\
\text { mãe e o bebê. [...] não sei se vou } \\
\text { poder participar. [...] não sei. }\end{array}$ \\
\hline
\end{tabular}

ao vínculo afetivo entre a mãe e filho, o que faz o Ministério da Saúde considerar o AM a única fonte alimentar para a crianças de 0 a seis meses de vida e após este período incluir alimentos complementares até dois anos ${ }^{(8)}$.

Diante disso, é importante considerarmos que a participação ativa dos pais no aleitar fortalece a atitude materna, devendo, portanto ser incentivada ainda no pré-natal. É comprovado que a participação dos pais no pré-natal de suas companheiras faz com que estas se mostrem mais preocupadas e dedicadas à saúde, diferente das que não têm este apoio, sem falar que os pais também merecem atenção, pois vivenciam os momentos de ansiedade, nervosismo e insegurança ocasionados no momento do parto ${ }^{(9)}$.

É de grande importância a participação dos pais nas atividades educativas do pré-natal, pois isto gera um maior envolvimento com a gravidez, proporcionando ao pai o conhecimento dos benefícios conjugais ${ }^{(9)}$.

Quadro 3 - Idéia Central e Discurso do Sujeito Coletivo (DSC) quanto ao questionamento: A amamentação interfere positivamente ou negativamente no seu relacionamento com sua esposa? Por quê? João Pessoa, 2011

\begin{tabular}{|ll|}
\hline IDEIA CENTRAL1 1 & Discurso do Sujeito Coletivo 1 \\
Não faz diferença & {$[. .$.$] não interfere em nada. [...] fica$} \\
alguma. & tudo do mesmojeito. [...] não interfe- \\
& reemnada. [...] não vai mudarnada.
\end{tabular}

IDEIA CENTRAL 2 Discurso do Sujeito Coletivo 2

Interfere positivamen- [...] positivamente, porque eu acho te, pois é a oportuni- que o pai principalmente tem que dade do pai apoiar a apoiar todos os seguimentos da mulher, e a criança mulher. [...] positivamente, porque sempre traz alegria. eu acho que o ser humano tem que ver o lado certo da coisa. [...] uma criança alegra muito o ambiente.

IDEIA CENTRAL3 Discurso do Sujeito Coletivo 3 Existe interferência [...] interferência tanto positiva negativa e positiva, comonegativa, pois nesseperiodo pois interfere no rela- fica complicado pra namorar micionamento do casal, nha esposa, mas em compensação porém a criança pre- tem a criança que na maioria das enche esta lacuna . vezespreenche a falta do namoro. [...] positivos e negativos, mais acredito que os positivos superam os pontos negativos.

\section{IDEIA CENTRAL 4 Discurso do Sujeito Coletivo 4}

Provoca um pouco [...] vai ter um pouco de estresse. de estresse. 
No quadro 2 observou-se que os pais se preocupam em dar apoio à sua companheira, em auxiliá-la nos momentos difíceis, que por vezes permeiam o ato de amamentar. Porém, também foram observados pais que não se percebem fazendo parte deste momento, que referem ser um momento só da mãe e do bebê. Esta percepção favorece o desmame precoce, visto que a mãe necessita ser apoiada pelo esposo, pela família e pelos profissionais de saúde para sentir-se motivada a amamentar.

Além disso, esta percepção do pai nos faz refletir quanto à qualidade da assistência pré-natal e puerperal que está sendo oferecida à família, quando estimula a sua participação no cuidado com o rescém-nascido $(\mathrm{RN})$ e, consequentemente, relativa à amamentação.

O incentivo dos pais ao AM é de suma importância, pois a amamentação é cercada de fatores que podem prejudicar o sucesso da mesma, dentre estes estão: fatores culturais, sociais e econômicos. A paternidade é de fato um envolvimento afetuoso com o filho, tal processo pode gerar grandes benefícios à nutriz e ao bebê, podendo o pai participar nos processos de gestar, parir e amamentar ${ }^{(10)}$.

Os pais nos primeiros dias de vida do $\mathrm{RN}$ tendem a ver o nascimento do filho da mesma forma que as mães, com o aumento da responsabilidade. Porém, com o passar dos dias, aquela preocupação sofre a interferência materna, passando esta a assumir a total responsabilidade sobre o RN, excluindo o pai do poder de decisão sobre os cuidados com o filho. Se houvesse, porém uma mudança na atitude materna, este fato poderia ser revertido com a contínua participação do pai no desenvolvimento do seu descendente ${ }^{(11)}$.

É importante a participação dos pais em todas as etapas vivenciadas pela mãe, tais como o período de gestação, no trabalho de parto, no parto, no pós-parto e em atendimentos pediátricos. Porém é explicita a dificuldade da participação paterna no que tange a inclusão dos mesmos nos programas de saúde em geral, esta dificuldade é expressa por algumas mães e profissionais de saúde quando relatam a falta de qualificação e/ou informação dos pais para participarem de tais momentos. No entanto, a inclusão paterna nos programas de saúde, serviria de fator motivacional para mãe no cuidar da criança, e ainda estreitaria os laços entre o pai e o filho ${ }^{(12)}$.

No quadro 3 observou-se os DSC com relação à interferência da amamentação no relacionamento dos pais com suas esposas, sendo esta percebida sob diferentes ângulos. Alguns afirmaram que a amamentação não interferia de forma alguma no relacionamento com sua esposa. Outros referiram que interferia posi- tivamente, pois percebiam a amamentação como uma oportunidade de estar mais próximo ao filho e a esposa, apoiando-a nesta prática. Também foi referido que a amamentação interferia tanto positivamente quanto negativamente no relacionamento com a esposa, uma vez que dificultava a intimidade do casal, sendo esta compensada pela convivência prazerosa com o filho recém-nascido. Houve também referência à interferência negativa, ou seja, a amamentação como fator estressante no relacionamento do casal.

A lactação é cercada por pontos positivos e negativos, que vão desde ao aumento do vinculo conjugal, proporcionado pelo bebê no momento do seu nascimento, como novas emoções que podem proporcionar uma aproximação do casal, bem como, o distanciamento físico e sexual, pois o nascimento de um filho traz consigo uma carga de responsabilidade sobre a mãe, que passa por vezes a desconsiderar as necessidades do companheiro ${ }^{(13)}$.

A falta de compreensão do pai quanto ao processo de lactação dificulta a adesão da mãe a esta prática.Assim, é de suma importância que haja um envolvimento dos pais nos programas de educação em saúde, orientando-os quanto a reprodução humana e o processo de lactação, possibilitando a estes uma visão mais ampla quanto à necessidade de incentivar, acompanhar e entender sua companheira em todas as fases de lactação ${ }^{(13-14)}$.

Um dos fatores do desmame precoce é justamente a falta de apoio do companheiro/esposo, vindo esta a trazer consequentemente prejuízo ao desenvolvimento infantil. Assim, o envolvimento paterno deve ser visto como uma estratégia de promoção e proteção ao AM, por ser fator determinante para decisão da mãe em amamentar, e ainda, se reflete na melhoria da vida conjugal ${ }^{(15)}$.

Muitas vezes os pais querem participar de todo este processo, mas sentem-se excluídos quando ouvem que amamentar é um processo que abrange apenas mãe-filho. Na visão popular os pais devem se afastar da amamentação por ser esta uma prática que deve ser desenvolvida apenas pelas mulheres. Este conceito fragiliza ainda mais o sucesso da amamentação, existindo portanto, a necessidade de ações que venham mudar esta percepção ${ }^{(16)}$.

\section{CONCLUSÃO}

A amamentação exclusiva não depende apenas da criança, e sim da motivação do trinômio pai, mãe e filho. Diante do exposto, esta pesquisa, buscou conhecer a participação e a percepção do pai com relação a pratica do AM.

Observou-se que a maioria dos pais se mostrou 
bastante interessado e empenhado em auxiliar a esposa, colocando-se à disposição dela e motivando-a durante o processo de aleitar, uma vez que, reconhecia as vantagens do AM para a criança. Porém, alguns deles não tinham tal conhecimento, e também não se incluíam nesta pratica, referindo ser um momento apenas da mãe e do bebê. Tal percepção vem comprometer o sucesso do AM, pela falta de incentivo dos pais a suas esposas, quanto a necessidade da continuidade desta prática tão importante para a saúde da criança.

Percebeu-se também que muitos deles acreditam que o AM poderia trazer mudanças significativas na vida conjugal. Uns consideravam que seria uma oportunidade de estreitar os laços afetivos com a esposa, enquanto outros referiram que interferiria na intimidade do casal, porém, considerava importante a presença do $\mathrm{RN}$ com eles, sendo este considerado fonte de muita alegria.

A pesquisa nos permitiu considerar a necessidade preemente de inserir os pais nas atividades de educação em saúde desenvolvidas durante o pré-natal e o puerpério, e as que se seguem na puericultura, uma vez que os cuidados com o bebê, entre estes a amamentação, são de responsabilidade do casal, devendo os pais serem motivados e capacitados para tal. Quando os pais forem incentivados aos cuidados com os filhos, com certeza auxiliarão as mães a superarem os obstáculos que surgem em torno da pratica do aleitamento materno e as motivará a continuarem exercendo esta atividade tão importante à saúde dos seus bebês.

\section{REFERÊNCIAS}

1. Montenegro CAB, Rezende Filho J. Rezende, Obstetrícia. Rio de Janeiro: Guanabara Koogan, 2010.

2. Kliegman RM, Behman RE, Jenson HB, Stanton BF. Nelson: Tratado de pediatria. Rio de Janeiro: Elsevier, 2009.

3. Pontes CM, Alexandrino AC, Osório MM. Participação do pai no processo da amamentação: vivências, conhecimentos, comportamentos e sentimentos, J. Pediatria. [Internet] 2008;84(4) [acesso em 22 set 2010]. Disponível: http://www.scielo.br/ scielo.php?script=sci_ arttext\&pid=S002175572008000400012\&lang=pt.

4. Brito RS, Oliveira EMF. Ações de cuidado desempenhadas pelo pai no puerpério. Esc Anna Nery Rev Enferm. [Internet] 2009;(13)3 [acesso em 14 mai 2011]. Disponível: http://www.scielo.br/scielo.php?script=sci arttext\&pid=S1414-8145200 9000300020\& lang=pt

5. Lefèvre F, Lefèvre AMC. O Discurso de Sujeito
Coletivo: um novo enfoque em pesquisa qualitativa (desdobramento). Caxias do Sul: EDUSC; 2005.

6. Braga DF, Machado MMT, Bosi MLM. Amamentação exclusiva de recém-nascidos prematuros: percepções e experiências de lactantes usuárias de um serviço público especializado. Rev. Nutrição. [Internet] 2008; (2)3 [acesso em 9 mai 2011]. Disponível: http://www. scielo.br/scielo.php?script=sci_arttext\&pid=S141552732008000300004\&la ng=pt.

7. Parada CMGL, Carvalhaes MABL, Winckler CC, Winckler LA, Winckler VC. Situação do aleitamento materno em população assistida pelo programa de saúde da família - PSF. Rev Latino-Am. Enfermagem. [Internet] 2005;(13)3 [acesso em 09 mai 2011]. Disponível: http://www.scielo.br/scielo.php?script=sci_ arttext\&pid=S0104-11692005000300016\&lan g=pt.

8. Pereira GS, Colares LGT, Carmo MGT, Soares EA. Conhecimentos maternos sobre amamentação entre puérperas inscritas em programa de prénatal. Cad Saúde Pública. [Internet] 2000;16(2) [acesso em 10 maio 2011]. Disponível: http://www. scielo.br/scielo.php?script $=$ sci_arttext\&pid=S0102311X2000000200016\&lan $\mathrm{g}=\mathrm{pt}$

9. Reberte LM, Hoga LAK. A experiência de pais participantes de um grupo de educação para saúde no pré-natal. Ciência Enferm. [Internet] 2010;16(1) [acesso em 15 maio 2011]. Disponível:http://www. scielo.cl/scielo.php?script $=$ sci_arttext\&pid $=$ S071795532010000100012\&lang $=\mathrm{pt}$

10. Pontes CM, Alexandrino AC, Osório MM. O envolvimento paterno no processo da amamentação: propostas de incentivo. Rev Bras Saúde Matern Infant.[Internet] 2009;9(4) [acesso em 11 maio 2011]. Disponível: http://www.scielo. br/scielo.php? script=sci_arttext \&pid=S151938292009000400003 \&lang $=-$ pt

11. Brito RS, Oliveira EMF. Aleitamento Materno: mudanças ocorridas na vida conjugal do pai, Rev Gaúcha Enferm. [Internet] 2006;(7)2 [acesso em 15 maio 2011]. Disponível: http://seer.ufrgs.br/index.php/ RevistaGauchadeEnfermagem/article/view /4596/2517

12. Carvalho MLM. Participação dos pais no nascimento em maternidade pública: dificuldades institucionais e motivações dos casais. Cad Saúde Pública. [Internet] 2003;19(2) [acesso em 12 maio 2011]. Disponível: http://www.scielosp.org/scielo.php?script=sci arttext\&pid $=$ S0102- 311X2003000800020\&tlng=pt

13. Brito RS, Enders BC, Soares VG. Lactação materna: 
a contribuição do pai. Rev Baiana Enferm. [Internet] 2004-2005;(19) [acesso em 15 maio 2011] Disponível: http://www.portalseer.ufba.br/index.php/enfermagem/ article/view/3895/2858

14. Silva RM, Pivetta HMF, Vieira EL, Battistel ALHT, Michelle Gracioli M, Righi RC. Incentivo ao aleitamento materno em unidades básicas de saúde de Santa MariaRS. Cogitare Enferm. [Internet] 2007;12(1) [acesso em 01 ago 2011]. Disponível: http://ojs.c3sl.ufpr.br/ojs2/ index.php/cogitare/article/view/8274/5785

15. Pinto TV. Promoção, proteção e apoio ao aleitamento materno na comunidade: revisão das estratégias no período pré-natal e após a alta. Arqui Med. [Internet] 2008;(2) [acesso em 14 maio 2011] Disponível: http:// www.scielo.oces.mctes.pt/scielo.php?script=sci_arttex t\& pid $=$ S087134132008000200005\&lng $=$ pt\&nrm $=$ iso

16. Pontes CM, Alexandrino AC, Osório MM. Participação do pai no processo da amamentação: vivências, conhecimentos, comportamentos e sentimentos. J. Pediatria. [Internet] 2010;(84)4 [acesso em 22 set 2010]. Disponível: http://www.scielo.br/scielo.php?script=sci_ arttext\&pid=S002175572008000400012\&lang $=$ pt. 